\title{
Sakarya Kadın Eğitim ve Kültür Merkezinden Hizmet Alan Kadınlarda Sosyal Dişlanma ve Yaşam Tatmininin İncelenmesi
}

DOI: $10.26466 /$ opus.611692

\begin{abstract}
$*$
Ayşe Sezen Serpen* - Erdinç Kalayc1** - Ece Parlak***

* Prof. Dr., Ankara Üniversitesi, Sağlık Bilimleri Fakültesi, Keçiören/Ankara/Türkiye

E-Posta: aysesezenbayoglu@gmail.com

ORCID: 0000-0002-6220-4709

** Arş.Gör, Ankara Üniversitesi, Sağllk Bilimleri Fakültesi, Keçiören/Ankara/Türkiye

E-Posta: kalaycierdinc@gmail.com ORCID: 0000-0001-8572-972X

*** Yüksek Lisans Öğrencisi, Ankara Üniversitesi, Sağlık Bilimleri Fak., Keçiören/Ankara/Türkiye

E-Posta: ecprlk@gmail.com

ORCID: $\underline{0000-0001-5154-9843}$

\section{$\ddot{O} z$}

Bu araştırma, Altındağ Belediyesi'ne bağlı bir kurum olan Sakarya Kadın Eğitim ve Kültür Merkezi'nden hizmet alan kadınların sosyal dışlanma ve yaşam tatminlerinin incelenmesi amactyla, 17 Eylül-21 Aralık 2018 tarihleri arasında gönüllü 133 kadın üzerinde yürütülmüş̧ür. Araştırmada veriler yüz yüze görüşme yöntemi kullanılarak toplanmış, verilerin elde edilmesinde Sosyo-demografik Bilgi Formu, Bayram, Bilgel ve Bilgel (2012) tarafindan Türkçe'ye uyarlanan "Sosyal Dışlanma Ölçeği" ve Bekmezci ve Mert (2018) tarafindan Türkçe'ye uyarlanan "Yaşam Tatmini Ölçeği" kullanılmıştır. Verilerin analizinde SPSS 22.0 kullanılmış, gerekli aritmetik ortalama, standart sapma ve yüzde değerler alınarak, kadınların sosyal dışlanma düzeyleri ile yaşam tatminleri, bazı sosyo-demografik değişkenlere göre t- testi ve Anova testi ile incelenmiştir. Araştırma sonucunda, Sakarya Kadın Ĕ̈itim ve Kültür Merkezi'nden hizmet alan kadınların, sosyal dışlanma düzeylerinin düşük, yaşam tatmini düzeylerinin görece yüksek oldŭ̆u; çalışma durumu, medeni durum, aile tipi gibi değişkenlerin kadınların, sosyal dışlanma düzeyleri ve yaşam tatminleri üzerinde istatistiksel olarak anlaml farklılığa neden olmadı̆̆ buna karşllık kadınların yaşlarının, yaşam tatminleri; eğitim durumlarının ise sosyal dışlanma düzeyleri üzerinde anlamlı farklılı̆̆a yol açtığı ve kadınların, sosyal dışlanma düzeyleri ile yaşam tatminleri arasında düşük düzeyde, anlamlı ve negatif bir ilişki olduğu saptanmıştır. Bu sonuçlar doğrultusunda, Kadın Eğitim Kültür Merkezlerinin ülke genelinde yaygınlaştırılması, merkezlerdeki hizmet ve programların içeriğinin genişletilip güncellenmesi ve merkezlerde sosyal hizmet uzmanlarının istihdam edilmesi önerilmiştir.
\end{abstract}

Anahtar Kelimeler: Sosyal dışlanma, yaşam tatmini, kadın eğitim ve kültür merkezleri. 


\title{
The Analysis of Social Exclusion and Life Satisfaction of the Served Women in the Sakarya Women's Education and Culture Center
}

\begin{abstract}
This research has been conducted among 133 volunteering women between the dates of 17 th of September-21st of December 2018 for the purpose of analyzing the social exclusion and life satisfaction of the served women in the Sakarya Women's Education And Culture Center, which is an affiliate institution of the Altında ğ Municipality. In the research the data were gathered through several ways including face-to-face interview method, the Socio-demographic information form, "Social Exclusion Scale" which was adapted by Bayram et al. and "Life Satisfaction Scale" which was translated into Turkish by Bekmezci and Mert (2018). SPSS 22.0 was used analyzing the data and by measuring the required arithmetic means, standard deviation and percentage values, the levels of social exclusion and life satisfaction of women; t-test per several socio-demographic variables and Anova test were used. The result of the study showed that the social exclusion levels of women receiving service from Sakarya Women's Education and Culture Center were low and their life satisfaction levels were relatively high; that variables such as working status, marital status and family type did not cause statistically significant differences on social exclusion levels and life satisfaction of women; in contrast, it was found that the age of women on their life satisfaction and education level on their social exclusion levels caused a significant difference and there was a low, significant and negative relationship between social exclusion levels and life satisfaction of women. In line with these results it is recommended to spread the Women's Education and Culture Centers in the country, improve and update the content of services and programs in the centers and hire social workers in these centers.
\end{abstract}

Keywords: Social exclusion, life satisfaction, women's education and culture centers 


\section{Giriş}

Mutluluk ve öznel esenlik (iyi olma hali) kavramlarına benzer bir anlamı ifade eden yaşam tatmini kavramı ilk kez 1961'de Neugarten tarafından tanımlanmıştır (Tabuk, 2009, s.29-30). Yaşam tatmini, günlük yaşamda bireyin, beklentilerinin ne kadarının karşılandığı ve hedeflerinin ne kadarına ulaşabildiğiyle ilgili bir kavramdır (Özgen, 2012, s.6; Yiğit, Dilmaç ve Deniz, 2011, s.4). Yaşam tatmini, bireyin yaşamını kendi benzersiz ve öznel ölçütlerine göre değerlendirdiği yargılayıcı bir süreçtir (Pavot ve Diener, 1993, s.164). Kısaca yaşam tatmini, "bir insanın yaşamını beğenmesi, onaylaması ve yaşamından memnun olması" olarak açılanabilir (Bekmezci ve Mert, 2018, s.168).

Yaşam tatmini kavramı her ne kadar kişisel değer ve algılara göre farklılık gösterse de günlük yaşamdan duyulan mutluluk, yaşamı anlamlı bulma, amaçlara ulaşma konusunda uyum, pozitif bireysel kimliğe sahip olma, fiziksel olarak bireyin kendini iyi hissetmesi, gelir seviyesi, çalışma ve iş hayatı, yaş ve cinsiyet, sosyal ve kültürel faktörler, politik ve ekonomik ortam, eğitim seviyesi ve medeni durum vb. faktörlerin bireyin yaşam tatminini etkilediği bilinmektedir (Demir, 2018, s.14-25; Özgen, 2012, s.79; Tabuk, 2009, s.31-35).

Sosyal dışlanma ise, ekonomik, sosyal, kültürel ve siyasal boyutları kapsayan karmaşık bir kavramdır ve tanımlanması oldukça zordur (Bhalla ve Lapeyre,1997; Chakravarty ve D'Ambrosio, 2006; Derin, 2017, s. 59; İmanlı, 2018, s.41; Karataşoğlu, 2014, s.8-9; Kenyon, Lyons ve Rafferty, 2002). Sosyal dışlanma, sosyal bütünleşmenin doğrudan karşıtı bir anlam taşır ve bireylerin içinde yaşadıkları topluma katılımını engelleyen sosyal, kültürel ve maddi yoksunluklara yol açan çok boyutlu bir süreç olarak tanımlanabilir (Bossert, D' ambrosio ve Peragine, 2007, s.778; Power ve Wilson, 2000; s.1; Robila, 2006, s.87).

Sosyal dışlanma ve yoksulluk kavramlarının birbiri yerine kullanıldığı hatta aynı anlamı ifade ettiği düşünülse de sosyal dışlanma kapsamı, dinamikliği ve çok boyutlu olması bakımından yoksulluğu, yoksulluğun nedenlerini ve etkilerini kapsayan bir kavramdır. Sosyal dışlanma yoksulluğun hem nedeni hem de sonucu olabilir (Akalın, 2006, s.41-42; Bölükbaşı, 2008, s.27-29). 
Sosyal dışlanmanın boyutlarını ve kapsamını ortaya çıkaran ve geliştiren pek çok faktör vardır. Küreselleşme süreci, işgücü piyasalarının yeniden yapılanması, gelir dağılımındaki bozulmalar, sosyal korumanın yetersiz kalması, ekonomik ve sosyal eşitsizlik, göç, aile yapısındaki değişim, cinsiyete dayalı ayrımcılık ve yaşa dayalı ayrımcılık bu faktörlere örnek olarak gösterilebilir (Akalın, 2006, s.26-31; Bölükbaş1, 2008; s.32-54; İmanlı, 2018, s.44-48; Karataşoğlu, 2014, s.11-19).

Ekonomik, toplumsal, siyasal alandan ve iş gücü piyasasından dışlanmak kadın ve erkek fark etmeksizin her ülkede ve toplumda sosyal dışlanmanın kendini gösterdiği alanlardır. Fakat günümüzde cinsiyete dayalı ayrımcılık, ataerki ideolojiler, kadına yüklenen toplumsal cinsiyet rolleri (ev işlerinin, çocuk, yaşlı ve engelli bireylerin bakımının kadının sorumluluğunda olması), kadının eğitime ve mesleki eğitime ulaşamamasından dolayı çalışma yaşamına katılamaması; çalışma yaşamına katılsa dahi kadın ve erkek arasındaki ücret, iş bulma ve terfi alma eşitsizliklerinin bulunması; çalışma yaşamında kadının sosyal haklardan ve sosyal güvenlikten yararlanamaması, mobbinge uğraması, kırsal alanda kadınların ücretsiz aile işçisi olarak çalıştııılması vb. nedenler kadınların, toplumsal, ekonomik ve siyasal hayata katılımlarının ikinci plana atılmasına ve sosyal dışlanma yaşamalarına neden olmaktadır (Bölükbaşı, 2008, s. 49-51; Buğra, 2018; Derin, 2017, s.78; Kocacık ve Gökkaya, 2005, s.195-196; Mayda ve Vurkun, 2018, s.217-224; Öztürk ve Çetin, 2009, s.2673, 2676, 2678, 2680).

Yapılan literatür araştırmasında, sosyal dışlanma ve yaşam tatminini bir arada ele alan araştırmaların sınırlı olduğu (Bayram ve Aytaç, 2010; Bayram, Bilgel ve Bilgel, 2012; Bayram, Sam, Aytaç, Aytaç ve Bilgel, 2012; Demir, 2018), doğrudan kadınlar üzerinde yapılan bir çalışmanın ise bulunmadığ görülmüştür. Yabancı literatür incelendiğinde ise sosyal dışlanma ve yaşam tatmini ilişkisini (Bellani ve D'Ambrosio, 2011; Shields, Price ve Wooden, 2009), çocuklar (Gross-Manos, 2017), yaşlilar (Dalhberg ve Mckee, 2018) ve göçmenler (Haisken De-New ve Sinning, 2010) üzerinde inceleyen sınırlı sayıda araştırma olduğu görülmektedir.

Türkçe literatür incelendiğinde sosyal dışlanmayla ilgili araştırmaların, LGTİ bireylerle (Danyeli Güzel, 2017), engellilerle (Karakan, 2018; Özgökçeler ve Bıçk1, 2010), gençlerle (Aksungur, 2006; Yücetürk, 2018) ve yaşlılarla (Genç ve Dalkılıç, 2013), mevsimlik tarım işçileriyle (Çakmak, 
2018), madde bağımlılarıyla (Derin, 2017), suçlularla (Aydoğan, 2018; Gökçearslan Çifci, 2017) şehit yakınları ve gazilerle (Nurdoğan, 2018), parçalanmış ailelerle (Yusufoğlu ve Kızmaz, 2016) ve engelli çocuğa sahip ailelerle (Yılmaz, 2018) yapıldığı görülmektedir. Sosyal dışlanmayla ilgili olarak ayrıca göç (Şener, 2018; Topgül, 2016) ve cinsiyet ayrımcılığı konularında (Dağ, 2016; Özpınar, Özpınar ve Çondur, 2013), şehirler bazında (Adaman ve Keyder, 2006; Karataşoğlu, 2014; Özhasar, 2013) ve etnik grupların sosyal dişlanmışlıklarının (Alacahan ve Duman, 2011; Deniz, Balcıoğlu ve Diktaş, 2016) incelenmesine yönelik araştırmaların da yapıldığ görülmektedir.

Türkçe literatürde yaşam tatminin, iş tatmini (Bir, 2017; Özyer, Irk ve Anaç, 2015), örgütsel ve sosyal destek (Yalçın, 2018), iş -aile çatışmaları (Çakmak Doruk, 2008; Ergin, 2018; Tabuk, 2009), meslekî tükenmişlik (İskender, 2015), yaşlı bireylerin sahip oldukları sosyal destek (Mutlu, 2012) ve emeklilikte finansal konularla ilişkisi (Öztürk ve Hazer, 2017) üzerine araştırmalar yapıldı̆̆ı görülmektedir.

Ülkemizde kadınların sosyal hayata katılımını artırmayı amaçlayan kurumların sayısı ve hizmetleri oldukça sınırlıdır. Ankara' da bir Altındağ Belediyesi hizmeti olarak sunulan "Kadın Eğitim ve Kültür Merkezleri" meslek edindirme, okuma yazma ve hobi - beceri kurslariyla (halk oyunu, dikiş nakış, ebru sanatı, koro vb.), sağlık, kadın hakları, hasta hakları, çocuk gelişimi, aile içi iletişim, öfke kontrolü, ilk yardım, diyabet, ağız ve diş sağlığı, çocuklarda üst solunum yolu hastalıkları, sağlıklı beslenme, alzaymır, depresyon, hırsızlığa karşı önlemler, anne ve çocuk sağlığı, adölesan eğitimi/psikolojisi/beslenmesi, genç anne adayları için sağlıklı emzirme yöntemleri, stres yönetimi, madde bağımlılığı eğitimi, kadına yönelik şiddet vb. konularında eğitim ve seminerleriyle; fitness salonları, hocalar eşliğinde aerobik, pilates, step, voleybol, dart, masa tenisi, futbol, basketbol ve yüzme dersleriyle kadınların sosyal hayata katılımını artırmayı amaçlayan kurumlardır (Altındağ Belediyesi Kadın Eğitim ve Kültür Merkezi Web Adresi). Bu araştırma, Türkiye'de kadınların sosyal dışlanma düzeyleri ile yaşam tatminlerinin incelenmesi amacıyla, Sakarya Kadın Eğitim ve Kültür Merkezi'nden hizmet alan kadınlar üzerinde yürütülmüştür. 


\section{Yöntem}

\section{Araştırma Evreni}

Araştırma evrenini Sakarya Kadın Eğitim ve Kültür Merkezinden hizmet alan kadınlar oluşturmaktadır. Araştırma, tam sayım yöntemi kullanılarak, 17 Eylül-21 Aralık 2018 tarihleri arasında bu merkezden hizmet alan ve çalışmaya katılmaya gönüllü olan toplam 133 kadın üzerinde yürütülmüştür.

\section{Veri Toplama Yöntemi ve Araçları}

Nicel yöntem benimsenerek yürütülen bu çalışmada yüz yüze görüşme tekniği kullanılarak araştırma verileri toplanmıştır. Araştırmada veri toplama aracı 3 bölümden oluşmaktadır. İlk bölüm kadınları tanıtıcı bulguları içeren "Sosyo-Demografik Bilgi Formu"; ikinci bölümde merkezden hizmet alan kadınların sosyal dışlanma düzeylerini belirlemek amacıyla Jehoel-Gijsbers ve Vrooman (2007) tarafından geliştirilen, Bayram, Bilgel ve Bilgel (2012) tarafından Türkçe literatüre geçerlilik ve güvenirlik analizi yapılarak kazandırılmış olan 5'li likert tipinde 35 maddeden oluşan "Sosyal Dışlanma Ölçeği"; son bölümde ise kadınların yaşam tatminlerini belirlemek amaciyla, Diener, Emmons, Larsen ve Griffin (1985) tarafından geliştirilen, Türkçe'ye uyarlanması Bekmezci ve Mert (2018) tarafından yapılan 5 madde ve 7'li likert tipi, 5 maddeden oluşan (1- Kesinlikle Katılmiyorum, 2- Katılmiyorum, 3- Kısmen Katılmıyorum, 4- Kararsızım, 5Kismen Katılıyorum, 6- Katılıyorum, 7- Kesinlikle katılıyorum) "Yaşam Tatmini Ölçeği" kullanılmıştır.

Yaşam Tatmini Ölçeğinden elde edilen yüksek değerler yüksek yaşam tatminini göstermektedir.

Sosyal dışlanma ölçeğinde maddi yoksunluk, sosyal haklara ulaşma, sosyal katılımcllık ve kültürel entegrasyon olmak üzere dört boyut mevcuttur. Ölçekte sosyal haklara ulaşma boyutu iki ayrı alt boyut şeklinde ele alınmaktadır. Birinci alt boyut sosyal haklar bağlamında kurumlardan ve yardımlardan faydalanabilmeyi kapsarken, ikinci alt boyut uygun ev ve güvenli çevreden faydalanabilmeyi kapsamaktadır. Ölçekte yer alan her bir madde "hiçbir zaman" ile "her zaman" arasında değişmektedir. 
Ölçeğin her bir boyutu için elde edilen yüksek değerler, sosyal dışlanma düzeyinin yüksek olduğunu göstermektedir. Diğer bir ifade ile, yüksek değerler maddi yoksunluğun yüksek olduğunu, kurumlardan ve yardımlardan yararlanılamadığını, uygun ev ve güvenli çevre koşullarına sahip olunmadığını, sosyal katılımcılığın düşük olduğunu (sosyal katılımcılığı başaramama), kültürel entegrasyon ve normlara uymanın başarılamad1ğını göstermektedir.

\section{Verilerin Analizi}

Verilerin çözümlenmesinde SPSS 22.0 kullanılmıştır. Elde edilen veriler oluşturulan SPSS veri tabanına girilerek gerekli ortalama, standart sapma ve yüzde değerler alınmıştır. Araştırmaya dahil edilen kadınların sosyal dışlanma düzeyleri ile yaşam tatminleri, çalışma durumu, medeni durum ve aile tipi değişkenlerine göre t-Testi; eğitim durumu ve yaş değişkenine göre Anova Testi ile incelenmiştir. Ortalama puanlar arasındaki farkın kaynağını belirlemek amacıyla Scheffe fark testi yapılmıştır.

Kadınların sosyal dışlanma düzeyleri ve yaşam tatminleri arasındaki ilişkiye ise Pearson Korelasyon Analizi ile bakılmıştır. Anlamlılık değerinin $p<0.05$ olduğu durumlar istatistiksel olarak anlamlı kabul edilmiştir.

\section{Bulgular}

\section{Kadınlara İlişkin Sosyo-Demografik Bulgular}

Araştırmaya katılan kadınların sosyo-demografik bilgileri Tablo 1'de gösterilmiştir.

Araştırma kapsamına alınan kadınların ortalama $(\bar{X}=41,60$ min: 19,00, max: 69,00) yaşında oldukları, \%27.8'inin 50 yaş ve üstünde, \%27.1'inin 40-49, \%26.3'ünün 31-39, \%18.8'inin 19-30 yaş gurubunda bulunduğu; yaklaşık üçte birinin (\%33.8) ilkokul, \%20.3'ünün ortaokul, \%29.3'ünün lise, \%16.5'ini üniversite mezunu oldukları saptanmıştır. Çizelgeden de izlenebileceği gibi, kadınların çoğunun çalışmadıkları (\%82.0), evli oldukları (\%70.7), yaşamlarının büyük bölümünü illerde geçirdikleri (\%75.2), 
çekirdek aile üyesi oldukları (\%75.2) ve yarısından fazlasının (\%59.4) 1 ya da 2 çocuğu olduğu saptanmıştır.

Tablo 1. Kadınları tanıtıcı sosyo-demografik bulgular

\begin{tabular}{|c|c|c|c|c|}
\hline & & & Sayı & $\%$ \\
\hline \multirow[t]{6}{*}{ Yaş } & $19-30$ yıl & & 25 & 18,8 \\
\hline & 31-39 y1l & & 35 & 26,3 \\
\hline & $40-49$ y1l & & 36 & 27,1 \\
\hline & 50 yıl ve üstü & & 37 & 27,8 \\
\hline & Toplam & & 133 & 100,0 \\
\hline & $\overline{\mathbf{X}}_{ \pm=41,60}$ & $\min : 19,00-\max : 69,00$ & & \\
\hline \multirow[t]{5}{*}{ Eğitim durumu } & İlkokul & & 45 & 33,8 \\
\hline & Ortaokul & & 27 & 20,3 \\
\hline & Lise & & 39 & 29,3 \\
\hline & Üniversite & & 22 & 16,5 \\
\hline & Toplam & & 133 & 100,0 \\
\hline \multirow[t]{3}{*}{ İş durumu } & Çalışıyor & & 24 & 18,0 \\
\hline & Çalışmiyor & & 109 & 82,0 \\
\hline & Toplam & & 133 & 100,0 \\
\hline \multirow[t]{3}{*}{ Medeni durum } & Evli & & 94 & 70,7 \\
\hline & Bekâr & & 39 & 29,3 \\
\hline & Toplam & & 133 & 100,0 \\
\hline \multirow{4}{*}{$\begin{array}{l}\text { Yaşamın büyük } \\
\text { bölümünün } \\
\text { geçtiği yer }\end{array}$} & Köy & & 11 & 8,3 \\
\hline & İlçe & & 22 & 16,5 \\
\hline & İl & & 100 & 75,2 \\
\hline & Toplam & & 133 & 100,0 \\
\hline \multirow[t]{3}{*}{ Aile tipi } & Çekirdek & & 100 & 75,2 \\
\hline & Geniş & & 33 & 24,8 \\
\hline & Toplam & & 133 & 100,0 \\
\hline \multirow[t]{4}{*}{ Çocuk sayısı } & Hiç yok & & 7 & 5,3 \\
\hline & $1-2$ & & 79 & 59,4 \\
\hline & 3 ve üstü & & 47 & 35,3 \\
\hline & Toplam & & 133 & 100,0 \\
\hline
\end{tabular}

Kadınların Sosyal Dışlanmalarına İlişkin Bulgular

Araştırmaya katılan kadınların sosyal dışlanmalarına ilişkin bulgular Tablo 2'de gösterilmiştir. 
Tablo 2. Kadınların sosyal dışlanma ölçeği ortalama puanları ve standart sapma değerleri

\begin{tabular}{|c|c|c|}
\hline & $\mathbf{X}$ & S \\
\hline 1. Su, elektrik, gaz, telefon gibi zorunlu ödemelerimi güçlükle yaparım. & 2,04 & 1,22 \\
\hline 2. Ödenmemiş faturalarım vardır. & 1,71 & ,98 \\
\hline 3. Maddi durumum hakkında endişelenirim. & 2,68 & 1,19 \\
\hline 4. Gelirimi giderimle denkleştirmeyi 2 yıl öncesine kıyasla daha zor buluyorum. & 2,75 & 1,25 \\
\hline 5. Buzdolabı, TV, çamaşır makinesi eskiyince veya bozulursa kolayca yenisini alırım. (R) & 3,59 & 1,22 \\
\hline 6. Temel ihtiyaçlarımı (yemek, giyecek vb.) karşılayamam. & 1,90 & 1,13 \\
\hline 7. Derneklere üye olmak isterim ancak üyelik aidatı beni düşündürür. & 2,48 & 1,50 \\
\hline 8. Benim için, kredi almak zordur. & 2,91 & 1,64 \\
\hline $\begin{array}{l}\text { 9. Kamu kurumlarında (hastane, vergi dairesi, nüfus müdürlüğü vb.) kötü muamele ile kar- } \\
\text { ş1laşırım. }\end{array}$ & 2,30 & 1,08 \\
\hline 10. Kamu kurumlarında (hastane vb.) randevu ve tedavi isteklerim çok uzak sürelere verilir. & 2,72 & 1,19 \\
\hline 11. Kamu kurumlarında (hastane, vergi dairesi, nüfus müdürlüğü vb.) sorun yaşarım. & 2,59 & 1,10 \\
\hline 12. Kredi ve sigorta müracaatların reddedilir. & 2,05 & 1,29 \\
\hline $\begin{array}{l}\text { 13. Yararıma olacak uygulamalar hakkım olduğu halde sonlandırılır veya hakkım hiç veril- } \\
\text { mez. }\end{array}$ & 2,22 & 1,02 \\
\hline 14. Yaşadığım çevrede olaylar çıkar. & 2,68 & 1,21 \\
\hline 15. İki yıl içerisinde başka bir yere taşınmayı düşünüyorum. & 2,40 & 1,51 \\
\hline 16. Yeni bir ev bulmam uzun sürdü ya da uzun sürebilir. & 2,64 & 1,47 \\
\hline 17. Yaşadığım çevrede komşuluk ilişkileri iyi değildir. & 2,30 & 1,35 \\
\hline 18. Yaşadığım çevrede kendimi güvende hissetmem & 2,40 & 1,31 \\
\hline 19. Evde tek başına olmaktan korkarım. & 1,98 & 1,10 \\
\hline 20. Yaşadığım çevrede gürültü vardır. & 2,86 & 1,39 \\
\hline 21. Yaşadığım çevre kirlidir. & 2,99 & 1,41 \\
\hline 22. Kendimi toplumdan dişlanmış hissederim. & 1,77 & 1,04 \\
\hline 23. Eğlenmek için ev dışında faaliyetlere katılırım. (R) & 3,34 & 1,36 \\
\hline 24. Sosyal ilişki kurabileceğim kişi sayısı çok azdır. & 2,35 & 1,26 \\
\hline 25. Çok sayıda arkadaşım vardır. (R) & 2,54 & 1,28 \\
\hline 26. Arkadaşlarımla toplanmayı, birlikte vakit geçirmeyi severim. (R) & 2,23 & 1,52 \\
\hline 27. Sırlarımı paylaşabileceğim arkadaşlarım yoktur, ya da çok azdır. & 2,45 & 1,19 \\
\hline 28. Arkadaşlarımdan çok az sosyal destek görürüm. & 2,13 & 0,99 \\
\hline 29. Diğer insanlarla olan ilişkilerimde sorun yaşarım. & 1,86 & 0,94 \\
\hline 30. Sağlık sorunlarım nedeniyle diğer insanlarla olan ilişkilerimde sorun yaşarım. & 1,73 & 1,04 \\
\hline 31. Arkadaşımın yararına olacaksa yalancı şahitlik yaparım. & 1,47 & 1,05 \\
\hline 32. Yakalanmadığım sürece kanunları çiğnemek sorun değildir. & 1,49 & 1,00 \\
\hline 33. Ücretli olarak çalışanların ek bir işte daha çalışmalarını uygun karşılarım. & 3,29 & 1,58 \\
\hline 34. İşsizlik parası veya sosyal yardım parası alanların ek iş yapmalarını uygun karşılarım. & 2,96 & 1,64 \\
\hline $\begin{array}{l}\text { 35. Başkalarının emekli veya sigorta karnelerini kullanarak ücretsiz muayene olunmasını } \\
\text { veya ilaç alınmasını uygun karşılarım. }\end{array}$ & 1,65 & 1,23 \\
\hline
\end{tabular}


düzeylerinin düşük olduğu belirlenmiştir. Kadınların, "Buzdolabı, TV, çamaşır makinesi eskiyince veya bozulursa kolayca yenisini alırım." ( $\bar{X}=3,59$ $\pm 1,22)$, "Eğlenmek için ev dışında faaliyetlere katılırım." ( $\bar{X}=3,34 \pm 1,36)$, "Ücretli olarak çalışanların ek bir işte daha çalışmalarını uygun karşılarım." ( $\bar{X}=3,29 \pm 1,58)$, "Yaşadığım çevre kirlidir." ( $\bar{X}=2,99 \pm 1,41)$, “Benim için, kredi almak zordur." ( $\bar{X}=2,90 \pm 1,64)$, "Yaşadığım çevrede gürültü vardır" ( $\bar{X}=2,86 \pm 1,39)$ tutum cümlelerine katıldıkları; "Arkadaşımın yararına olacaksa yalancı şahitlik yaparım." ( $\bar{X}=1,47 \pm 1,05)$, "Yakalanmad1ğım sürece kanunları çiğnemek sorun değildir.” ( $\bar{X}=1,49 \pm 1,00)$, “Başkalarının emekli veya sigorta karnelerini kullanarak ücretsiz muayene olun-

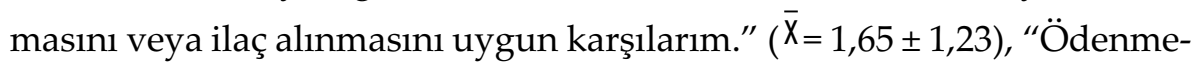
miş faturalarım vardır." ( $\bar{X}=1,71 \pm 0,98)$ tutum cümlelerine ise katılmadıkları saptanmıştır.

Özpınar ve diğ. (2013) ve Bradshaw ve diğ. (2000) yaptıkları çalışmalarda kadınların, sosyal dışlanma düzeylerinin erkeklere oranla daha yüksek olduğu sonucuna ulaşmışlardır. Dağ (2016) çalışmasında ise 65 + kadınların, kamusal alandan dişlanma, yoksulluk, eğitimsizlik, ataerkil ideoloji ve kadınların toplumdaki ikincil konumu vb. nedenlerden dolayı sosyal dışlanma yaşadıkları sonucuna ulaşmıştır.

\section{Kadınların Yaşam Tatminlerine İlişkin Bulgular}

Araştırmaya katılan kadınların yaşam tatminlerine ilişkin bulgular Tablo 3 'te gösterilmiştir.

Tablo 3. Kadınların yaşam tatmini ölçeği ortalama puanlarn ve standart sapma değerleri

\begin{tabular}{lll}
\hline & $\mathbf{X}$ & $\mathbf{S}$ \\
\hline 1. Pek çok yönden yaşamım ideale yakın. & 3,77 & 1,91 \\
\hline 2. Yaşam koşullarım mükemmel. & 3,65 & 1,93 \\
\hline 3. Yaşamım beni tatmin ediyor. & 4,20 & 2,04 \\
\hline 4. Şimdiye kadar, yaşamda istediğim önemli şeyleri elde ettim. & 3,94 & 1,83 \\
\hline 5. Hayatımı bir daha yaşama şansım olsaydı, hemen hemen hiçbir şeyi değiştirmezdim. & 3,81 & 1,99 \\
\hline
\end{tabular}


Tablo 3'te araştırmaya katılan kadınların yaşam tatminlerine ilişkin bulgular incelendiğinde; kadınların yaşam tatmini ölçeği ortalama puanlarının $\bar{X}=3,87$ olduğu; en çok "Yaşamım beni tatmin ediyor." ( $\bar{X}=4,20 \pm 2,04)$, "Şimdiye kadar, yaşamda istediğim önemli şeyleri elde ettim." ( $\bar{X}=3,94 \pm$ 1,83), "Hayatımı bir daha yaşama şansım olsaydı, hemen hemen hiçbir şeyi değiştirmezdim." ( $\bar{X}=3,81 \pm 1,99)$ tutum cümlelerine katıldıkları görülmektedir.

Yürütülen bu çalışmada kadınların yaşam tatmini ortalama puanlarının Tabuk (2009) ( $x=3.3824, s=1.0955)$ ve Çakmak Doruk (2008) ( $x=3.46$, $\mathrm{s}=1.02)$ tarafından yürütülen çalışmalardaki katılımcıların yaşam tatmini

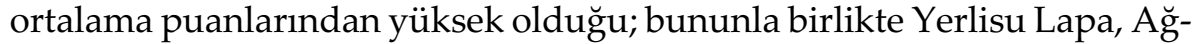
yar ve Bahadır (2012) tarafından yürütülen çalışmadaki katılımcıların, yaşam tatmini ortalama puanından $(x=4,67, s=1.05)$ düşük olduğu belirlenmiştir. Söz konusu bu çalışmaların örneklemi sadece kadınlardan oluşmamakla birlikte, yürütülen bu çalışmadaki yaşam tatmini ortalama puanlarının diğer çalışmalardan yüksek olduğu söylenebilir.

\section{Bazı Değişkenlere Göre Kadınların Sosyal Dışlanma Düzeyleri ve Yaşam Tatminlerinin İncelenmesi}

Bu kapsamda, araştırmaya katılan kadınların çalışma durumları, medeni durumları, üyesi oldukları aile tipi, yaşları ve eğitim durumlarına göre sosyal dışlanma düzeyleri ve yaşam tatminleri incelenmiştir.

Tablo 4. Çalışma durumlarına göre kadınların sosyal dışlanmaları ve yaşam tatmininin incelenmesine ilişkin t-testi sonuçları

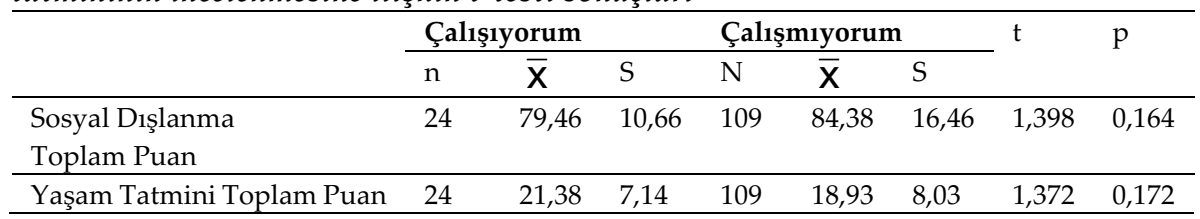

Araştırmaya dahil edilen kadınların çalışma durumlarına göre sosyal dışlanma düzeyleri değerlendirildiğinde; çalışmayan kadınların sosyal dışlanma düzeylerinin, çalışan kadınların sosyal dışlanma düzeylerinden 
daha yüksek olduğu ( $\bar{X}=84,38, \bar{X}=79,46)$, bununla birlikte kadınların çalışma durumlarına göre sosyal dışlanma ölçeği ortalama puanlarının istatistiksel olarak farklılaşmadığı $(\mathrm{p}>0,05)$ saptanmıştır.

Kadınların çalışma durumlarına göre "yaşam tatmini ölçeği" puanları değerlendirildiğinde; çalışan kadınların yaşam tatminlerinin çalışmayanlara göre yüksek olduğu $(\bar{X}=21,38, \bar{X}=18,93)$, buna karşılık ortalama puanlar arasındaki farkın istatistiksel olarak anlamlı olmadığı $(p>0,05)$ görülmüştür.

Tablo 5. Medeni durumlarına göre kadınların sosyal dışlanmaları ve yaşam tatmininin incelenmesine ilişkin t-testi sonuçları

\begin{tabular}{|c|c|c|c|c|c|c|c|c|}
\hline & \multicolumn{3}{|c|}{ Evli } & \multicolumn{3}{|c|}{ Bekar } & \multirow[t]{2}{*}{$\mathrm{t}$} & \multirow[t]{2}{*}{$\mathrm{p}$} \\
\hline & $\mathrm{n}$ & $\bar{x}$ & $\mathrm{~s}$ & $\mathrm{n}$ & $\bar{x}$ & $S$ & & \\
\hline Sosyal Dışlanma Toplam Puan & 94 & 82,77 & 15,06 & 39 & 85,23 & 17,09 & 0,826 & 0,411 \\
\hline Yaşam Tatmini Toplam Puan & 94 & 19,79 & 7,86 & 39 & 18,38 & 8,03 & 0,931 & 0,354 \\
\hline
\end{tabular}

Kadın eğitim ve kültür merkezinden hizmet alan kadınların medeni durumlarına göre sosyal dışlanma düzeyleri incelendiğinde; bekar kadınların sosyal dişlanmışlık düzeyleri evli kadınlara göre göreli olarak yüksek olmakla birlikte $(\bar{X}=85,23, \bar{X}=82,77)$ ortalama puanları arasındaki fark anlamlı bulunmamıştır ( $\mathrm{p}>0,05)$.

Kadınların medeni durumlarına göre yaşam tatminleri incelendiğinde ise; evli kadınların yaşam tatminlerinin bekar kadınların yaşam tatminlerinden $(\bar{X}=19,79, \bar{X}=18,38)$ yüksek olduğu ancak farkın istatistiksel olarak anlamlı olmadığı $(p>0,05)$ saptanmıştır. Bir (2017) de çalışmasında benzer şekilde evli kadınların ( $\overline{\mathrm{X}}=22.77)$ yaşam tatminlerinin, bekar kadınların ( $\overline{\mathrm{X}}$ $=19,24$ ) yaşam tatminlerinden daha yüksek değerlere sahip olduğunu bulmuştur.

Tablo 6. Aile tipine göre kadınların sosyal dışlanmalar ve yaşam tatminlerinin incelenmesine ilişkin t-testi sonuçları

\begin{tabular}{|c|c|c|c|c|c|c|c|c|}
\hline & \multicolumn{3}{|c|}{ Çekirdek } & \multicolumn{3}{|c|}{ Geniş } & \multirow[t]{2}{*}{$t$} & \multirow[t]{2}{*}{$p$} \\
\hline & $\mathrm{n}$ & $\overline{\mathrm{x}}$ & $S$ & $\mathrm{~N}$ & $\bar{x}$ & $S$ & & \\
\hline $\begin{array}{l}\text { Sosyal Dişlanma } \\
\text { Toplam Puan }\end{array}$ & 100 & 83,76 & 15,63 & 33 & 82,77 & 15,96 & 0,347 & 0,729 \\
\hline Yaşam Tatmini Toplam Puan & 100 & 19,60 & 7,53 & 33 & 18,70 & 9,04 & 0,567 & 0,572 \\
\hline
\end{tabular}


Tablo 6'dan da izlenebileceği gibi, çekirdek aileye sahip olan kadınların hem sosyal dışlanma düzeylerinin ( $\bar{X}=83,76, \bar{X}=82,77)$ hem de yaşam tatminlerinin $(\bar{X}=19,60, \bar{X}=18,70)$ göreli olarak geniş aile üyesi kadınlardan daha yüksek olduğu; buna karşılık aile tipi değişkeninin kadınların sosyal dışlanma düzeyi ve yaşam tatmini üzerinde istatistiksel bir farklılık yaratmadığı gözlenmiştir $(p>0,05)$.

Tablo 7. Yaşa göre kadınların sosyal dışlanmaları ve yaşam tatminlerinin incelenmesine ilişkin Anova testi sonuçlan

\begin{tabular}{llllllll}
\hline & Yaş & $\mathrm{n}$ & $\overline{\mathbf{X}}$ & $\mathrm{S}$ & $\mathrm{F}$ & $\mathrm{p}$ & $\begin{array}{l}\text { Anlaml } \\
\text { Fark }\end{array}$ \\
\hline Sosyal & $\mathbf{1 9 - 3 0}$ & 25 & 76.92 & 14.06 & 2.10 & 0.103 & - \\
Dişlanma & $\mathbf{3 1 - 3 9}$ & 35 & 86.31 & 13.02 & & & \\
Toplam & $\mathbf{4 0 - 4 9}$ & 36 & 83.25 & 15.90 & & & \\
& $\mathbf{5 0}$ ve üstü & 37 & 85.48 & 17.87 & & & \\
\hline Yaşam & $\mathbf{1 9 - 3 0}$ & 25 & 22.80 & 5.19 & 4.05 & $0.009^{* * *}$ & $1-3$ \\
Tatmini & $\mathbf{3 1 - 3 9}$ & 35 & 17.89 & 7.62 & & & \\
Toplam & $\mathbf{4 0 - 4 9}$ & 36 & 16.78 & 8.49 & & & \\
& $\mathbf{5 0}$ ve üstü & 37 & 21.00 & 8.17 & & & \\
\hline
\end{tabular}

Tablo 8. Eğitim durumuna göre kadınların sosyal dışlanmalarn ve yaşam tatmininin incelenmesine ilişkin Anova testi sonuçları

\begin{tabular}{|c|c|c|c|c|c|c|c|c|}
\hline & $\begin{array}{l}\text { Eğitim } \\
\text { rumu }\end{array}$ & Du- & $\mathrm{n}$ & $\bar{x}$ & $S$ & $\mathrm{~F}$ & $\mathrm{p}$ & $\begin{array}{l}\text { Anlaml } \\
\text { Fark }\end{array}$ \\
\hline Sosyal & lkokul & & 45 & 91.4 & 17.62 & 7.114 & 0.000 & $1-3$ \\
\hline Dişlanma & Ortaokul & & 27 & 81.4 & 15.78 & & & \\
\hline \multirow[t]{2}{*}{ Toplam } & Lise & & 39 & 77.3 & 12.58 & & & \\
\hline & Üniversite & & 22 & 80.9 & 8.76 & & & \\
\hline Yaşam & lkokul & & 45 & 17.9 & 9.33 & 0.848 & 0.470 & - \\
\hline Tatmini & Ortaokul & & 27 & 19.4 & 8.60 & & & \\
\hline \multirow{2}{*}{ Toplam } & Lise & & 39 & 20.5 & 6.43 & & & \\
\hline & Üniversite & & 22 & 20.3 & 6.1 & & & \\
\hline
\end{tabular}

Araştırma kapsamına alınan kadınların sosyal dışlanma düzeyleri yaş değişkenine göre incelendiğinde; 31-39 yaşındaki kadınların sosyal dışlanma düzeylerinin en yüksek ( $\bar{X}=86,31)$; 19-30 yaşındaki kadınların sosyal dışlanma düzeylerinin ise en düşük $(\bar{X}=76,95)$ olduğu saptanmıştır. Yapılan istatistik analiz sonuçları; kadınların sosyal dışlanma düzeylerinin yaşa göre değişmediğini göstermiştir ( $F=2.10$, p>0.05) (Tablo 7). 
Bayram ve diğ. (2010) ile Jehoel-Gijsberg ve Vrooma (2007) tarafından yapılan çalışmalarda ise gençlerin, yaşlılara oranla daha fazla sosyal dışlanmaya maruz kaldıkları sonucuna ulaşılmıştır.

Kadınların yaşam tatminleri, yaş değişkenine göre incelendiğinde; en yüksek yaşam tatmininin 19-30 yaşındaki kadınlarda $(\bar{X}=22,80)$, en düşük yaşam tatmininin ise 40-49 yaşındaki kadınlarda $(\bar{X}=16,78)$ olduğu, yaşam tatminin yaşa bağı olarak istatistiksel olarak değiştiği $(\mathrm{F}=4.05, \mathrm{p}<0.001)$ saptanmıştır. Scheffe fark testi sonucuna göre 19-30 yaşındaki kadınların yaşam tatmini, 40-49 yaşındaki kadınların yaşam tatmininden daha yüksektir (Tablo 7).

Demir (2018) ise 45 ve 60 yaş üstü yaşlı bireylerle yaptığı çalışmada, yaşlanma ile yaşam tatmini arasında pozitif bir ilişki olduğunu saptamıştır. Çalışmalardaki bu farklılıkların kaynağının çalışma gruplarının sosyodemografik özelliklerinin farklı olmasından kaynaklanabileceği düşünülmektedir.

Araştırma kapsamına alınan kadınların eğitim durumlarına ilişkin ANOVAtesti sonuçları incelendiğinde; ilkokul mezunu kadınların sosyal dışlanma ölçeği ortalama puanlarının en yüksek $\left(\bar{X}_{=} 91,4\right)$; lise mezunu kadınların sosyal dışlanma ölçeği ortalama puanlarının en düşük ( $\bar{X}_{=}$ $76,95)$ olduğu; üniversite ve ortaokul mezunu kadınları sosyal dışlanma ölçeği ortalama puanlarının birbirine yakın olduğu ( $\bar{X}=80,9, \bar{X}=81,4)$ bulunmuştur. Anova sonuçlarına göre; kadınların sosyal dışlanmalarının eğitim durumuna göre farklılaştığ 1 ( $F=7.11$, $\mathrm{p}<0.001)$; ilkokul mezunu kadınların sosyal dışlanma puanlarının lise mezunu kadınların sosyal dışlanma puanlarından ( $\bar{X}=91,4, \bar{X}=77,3)$ anlamlı biçimde farklı olduğu bulunmuştur (Tablo 8).

Bayram ve diğ. (2010) ve Devicienti ve Poggi (2007) tarafından yapılan çalışmalar da benzer biçimde eğitim seviyesi yüksek olan kadınların, sosyal dışlanma seviyelerinin daha düşük olduğu sonucuna ulaşılmıştır.

Kadınların eğitim durumuna göre yaşam tatminleri değerlendirildiğinde ise; lise ve üniversite mezunu kadınların yaşam tatminlerinin hemen hemen aynı olduğu ( $\bar{X}=20,5, \bar{X}=20,3)$, ilkokul mezunu kadınların yaşam tatminlerinin ise en düşük $(\bar{X}=17,9)$ olduğu bulunmuştur. Yapılan is- 
tatistik analiz sonuçlarında kadınların eğitim durumlarına göre yaşam tatminlerinin anlamlı biçimde farklılaşmadığı saptanmıştır $(\mathrm{F}=0.85, \mathrm{p}>0.05)$. (Tablo 8).

$\mathrm{Bu}$ çalışmanın sonuçlarına paralel olarak; Bayram ve diğ. (2010) ve Çakmak Doruk (2008) çalışmasında, eğitim düzeyi yüksek olan kadınların, yaşam tatmini düzeylerinin daha yüksek olduğunu ortaya koymuştur. Bir (2017) de çalışmasında, katılımcıların eğitim durumları ile yaşam tatmini değerleri arasında anlamlı bir farklılık bulunmadığ ulaşmıştır.

Kadınların Sosyal Dışlanma Düzeyleri ve Yaşam Tatminleri Arasındaki İlişkinin İncelenmesi

Kadınların sosyal dışlanma düzeyleri ve yaşam tatminleri arasındaki ilişkinin incelenmesi amacı ile Pearson Korelasyon Analizi yapılmış, sonuçlar Tablo 9'da sunulmuştur.

Tablo 9. Kadınların sosyal dışlanmaları ve yaşam tatminleri arasındaki ilişkinin incelenmesine ilişkin Pearson Korelasyon Analizi sonuçları

\begin{tabular}{lll}
\hline & Sosyal Dişlanma & Yaşam Tatmini \\
\hline Yaşam Tatmini &,$- 233^{* *}$ & - \\
\hline Sosyal Dişlanma & - &,$- 233^{* *}$ \\
\hline${ }^{* *} p>0.01$ & &
\end{tabular}

Araştırma kapsamına alınan kadınların sosyal dışlanma ve yaşam tatmini ölçeklerinden aldıkları puanlar arasındaki ilişki incelenmiş; sosyal dışlanma ve yaşam tatmini arasında düşük düzeyde, anlamlı ve negatif bir ilişki saptanmıştır. Buna göre; sosyal dışlanma azaldıkça yaşam tatmini artmaktadır.

Yapılan diğer çalışmalarda da sosyal dışlanmışlık ve yaşam tatmini arasında negatif yönde bir ilişki olduğu sonucu ortaya konmuştur (Bayram ve Aytaç, 2010; Bayram ve diğ. 2012; Bellani ve D'Ambrosio, 2011; Dalhberg ve Mckee, 2018; Shields ve diğ., 2009). Lee ve Cagle'nin (2017) yaptıkları çalışmada da sosyal dışlanma faktörlerinin yaşlı erişkinlerin yaşam tatmini üzerine etki ettiği bulunmuştur.

\section{Sonuç ve Öneriler}


Türkiye'de kadınların sosyal dışlanmışlıkları ile yaşam tatminleri arasındaki ilişkinin incelenmesi amacıyla, Sakarya Kadın Eğitim ve Kültür Merkezi'nden hizmet alan kadınlarla yürütülen bu araştırmada sonuç olarak;

- Kadınların sosyal dişlanma düzeylerinin düşük, yaşam tatminlerinin ise göreli olarak yüksek olduğu,

- Çalışma durumu, medeni durum, aile tipi gibi değişkenlerin kadınların sosyal dışlanma düzeyleri ve yaşam tatminleri üzerinde istatistiksel olarak anlamlı olmasa da etkili olduğu,

- Kadınların yaşlarının, yaşam tatminleri; eğitim durumlarının ise sosyal dışlanma düzeyleri üzerinde anlamlı farklılığa yol açtığı,

- Sakarya Kadın Eğitim ve Kültür Merkezi'nden hizmet alan kadınların sosyal dışlanma düzeyleri ile yaşam tatminleri arasında düşük düzeyde, anlamlı ve negatif bir ilişki olduğu saptanmıştır.

Bu merkezden hizmet alan kadınların dezavantajlı sayılabilecek bir bölgede yaşamlarını sürdürüyor olmalarına karşın sosyal dışlanma düzeylerinin düşük, yaşam tatminlerinin yüksek olduğu göz önünde bulundurulduğunda;

- Toplumsal cinsiyet eşitliğini sağlamada rol üstlenecek Kadın Eğitim Kültür Merkezlerinin ülke genelinde yaygınlaştırılması,

- Bu merkezlerdeki hizmet ve programların içeriğinin kadınların domestik rollerini pekiştirecek eğitim ve faaliyetlerin dışında genişletilip güncellenmesi,

- Kadınların yaşam tatminlerinin yükseltilmesi ve sosyal dışlanma düzeylerinin azaltılabilmesi için grup çalışmaları ve bireysel görüşmelerle kadınların ihtiyaçlarına cevap vererek refahlarını yükseltecek sosyal hizmet uzmanlarınin bu merkezlerde istihdam edilmesi,

- Kadınların sosyal dışlanma düzeylerinin azaltılması, sosyal dışlanma süreçlerinden dolayı oluşan sorunların çözümü ve kadınlara yönelik güçlendirme temelli çalışmalar yapılması için sosyal hizmet uzmanı, psikolog gibi insan ile çalışan meslek gruplarının istihdam edilmesi önerilebilir. 
EXTENDED ABSTRACT

\title{
The Analysis of Social Exclusion and Life Satisfac- tion of the Served Women in the Sakarya Women's Education and Culture Center
}

\author{
Ayşe Sezen Serpen - Erdinç Kalayc1 - Ece Parlak \\ Ankara University
}

While life satisfaction is a concept about how much of the individual's expectations are met in daily life and how much the individual can achieve own goals, social exclusion has a direct opposite meaning to social integration and can be defined as a multidimensional process that leads to social, cultural and material deprivations that prevent individuals from participating in the society they live in.

In the contemporary day gender-based discrimination, patriarchal ideologies, gender roles attributed to women, women's inability to participate in working life due to lack of access to education and vocational training; the existence of inequalities in wages, employment and promotion between men and women, even if they participate in working life; women's inability to benefit from social rights and social security in work life, mobbing, women working in rural areas as unpaid family workers and similar other reasons cause women's participation in social, economic and political life to be put on the secondary importance and social exclusion.

In the literature research, it was seen that the studies that deal with social exclusion and life satisfaction were limited and there was no study conducted directly on women.

This study was conducted on 133 women volunteered The necessary arithmetic mean, standard deviation and percentage values were taken and $t$-test was used according to the variables of social exclusion levels and life satisfaction, working status, marital status and family type between the dates 17 September - 21 December 2018 in order to investigate the social exclusion and life satisfaction of women receiving service from Sakarya Women's Education and Culture Center, an institution of Altındağ Municipality. The study which was conducted by adopting 
quantitative method, research data were collected using face to face interview technique. Data collection tool consists of 3 parts. The first part is the socio-demographic information form, which includes findings over women; In the second part, "Social Exclusion Scale" consisting of 35 items of 5-point Likert type, which was developed by Jehoel-Gijsbers and Vrooman (2007) and was validated by Bayram et al. and translated into Turkish; in the last section, "Life Satisfaction Scale" was used which consists of 7-points likert type 5 items, and was developed by Diener et al. (1985) and adapted to Turkish by Bekmezci and Mert (2018). SPSS 22.0 was used in the analysis of the data; Anova test was used depending on the educational status and age. Scheffe difference test was used to determine the source of the difference between the mean scores. The relationship between social exclusion levels and life satisfaction of women was examined by Pearson Correlation Analysis. When the responses of the women participating in the study on the items of social exclusion scale were examined they were found to agree with the attitude sentences, "Lacks consumer durables due to financial deficits", "Does not/hardly go out for amusement", "Acceptance of paid second job", "Dirty neighborhood", "Has difficulties in obtaining a loan", "Noisy neighborhood". Attendance sentences; whereas they do not agree with the sentences "A false testimony is allowed if a friend faces trial", "Breaching the law is not a problem as long as one does not get caught", "Acceptance of the usage of others' health or insurance documents in order to being examined or treated free of charge", "Has arrears of payment". When the findings related to life satisfaction of women were examined; mostly the following sentences were agreed: "I am satisfied with my life", "So far I have gotten the important things I want in life", "If I could live my life over, I would change almost nothing".

The result of the study showed that the social exclusion levels of women receiving service from Sakarya Women's Education and Culture Center were low and their life satisfaction levels were relatively high; that variables such as working status, marital status and family type did not cause statistically significant differences on social exclusion levels and life satisfaction of women; in contrast, it was found that the age of women on their life satisfaction; education level on their social exclusion levels 
caused a significant difference and there was a low, significant and negative relationship between social exclusion levels and life satisfaction of women. In line with these results, considering the role of these centers in achieving gender equality, spreading of Women's Education and Culture Centers throughout the country, expanding and updating the content of the services and programs in these centers beyond the education and activities that will reinforce the domestic roles of women, to employ social workers in these centers to meet the needs of women through group work and individual interviews in order to decrease the level of social exclusion of women while increasing their satisfaction levels of life.

\section{Kaynakça / References}

Adaman, F. ve Keyder, Ç. (2005). Türkiye'de büyük kentlerin gecekondu ve çöküntü mahallelerinde yaşanan yoksulluk ve sosyal dışlanma, Türkiye Raporu. 20.03.2019 tarihinde http://ec.europa.eu/employment social/social inclusion/docs/2006/study turkey tr.pdf adresinden erişilmiştir.

Adaman, F. ve Ardıç, O.P. (2008). Social exclusion in the slum areas of large cities in Turkey. New Perspectives on Turkey, 38(1), 29-60.

Akalın, M. (2006). Yoksulluk, sosyal dışlanma ve işsizlik sarmalı.Yayımlanmamış Yüksek Lisans Tezi, Anadolu Üniversitesi, Eskişehir.

Aksungur, U. (2006). Experiences of social exclusion of the youth living in Altında $\breve{g}$, Ankara. Yayımlanmamış Yüksek Lisans Tezi, ODTÜ, Ankara.

Alacahan, O. ve Duman, B. (2011). Dışlanma, ayrımcllık, mezhep ve etniklikler arası eşitsizlikler. Sosyal Bilimler Dergisi, 8(1), 1-29.

Altındağ Belediyesi. (t.y) Kadın eğitim ve kültür merkezi. Erişim Tarihi: 01.04.2019, https://www.altindag.bel.tr/\#!kadin egitim kultur merkezleri

Aydoğan, R. (2018). Cezaevi sonrası denetimli serbestlik sürecindeki hükümlülerin suç, damga ve sosyal dışlanma bağlamında incelenmesi. Yayımlanmamış Yüksek Lisans Tezi. Mimar Sinan Güzel Sanatlar Üniversitesi, İstanbul.

Bayram, N., Aytaç, S. (2010). Yaşam tatmini ve sosyal dışlanma. Industrial Relationsand Human Resources Journal (ISGUC), 12(4), 79-92.

Bayram, N., Bilgel, F. ve Bilgel, N. G. (2012). Social exclusion and quality of life: an empirical study from Turkey. Social Indicators Research, 105(1), 109-120. 
Bayram, N., Sam, N., Aytaç, S., Aytaç, M. ve Bilgel, N. (2012). Poverty, social exclusion, and life satisfaction: study fromTurkey. Journal of Poverty, 16(4), 375-391.

Bekmezci, M. ve Mert, İ.S. (2018). Yaşam tatmini ölçeğinin Türkçe geçerlilik ve güvenirlilik çalışması. Toros Üniversitesi İISBF Sosyal Bilimler Dergisi, 5(8), 166-177.

Bellani, L. ve D'Ambrosio, C. (2011). Deprivation, social exclusion and subjective well-being. Social Indicators Research, 104, 67-86.

Bhalla, A. ve Lapeyre, F. (1997). Social exclusion: toward an analytical and operational framework. Development and Change, 28, 413-433.

Bir, Y. (2017). İş ve yaşam tatmini arasındaki ilişkiye etki eden demografik değişkenler üzerine araştırma: Bir uluslararası firma uygulaması. Yayımlanmamış Yüksek Lisans Tezi, Çağ Üniversitesi, Mersin.

Bossert, W. ve D'ambrosio, C. ve Peragine, V. (2007). Deprivation and social exclusion. Economica, 74, 777-803.

Bölükbaşı, B. (2008). Türkiye’de sosyal dışlanma ve yoksulluk. Yayımlanmamış Yüksek Lisans Tezi, Marmara Üniversitesi, İstanbul.

Bradshaw, J., Williams, J., Levitas, R., Pantazis, C., Patsios, D., Townsend, P., Gordon, D. and S. Middleton (2000). The relationship between poverty and social exclusion in Britain. Paper presented at the 26th General Conference of the International Association for Research in Income and Wealth, Cracow, Poland. 25.07.2019 tarihinde http://www.iariw.org/papers/2000/bradshaw.htm adresinden erișilmiștir.

Buğra, A. (2018, 8 Mart). Karşılaştırmalı verilerle Türkiye'de kadın-erkek eşitsizliği. 01.04.2019 tarihinde https://sarkac.org/2018/03/turkiyede-kadin-erkek-esitsizligi/ adresinden erişilmiştir.

Chakravarty, S.R. ve D'Ambrosio, C. (2006). The measurement of social exclusion. Review of Income and Wealth, 52(3), 377-398.

Çakmak Doruk, N. (2008). Organizasyonlarda iş-aile ve aile-iş çatışmalarının bireylerin performanslar üzerindeki etkisinde iş ve yaşam tatmininin rolü. Yayımlanmamış Yüksek Lisans Tezi. Erciyes Üniversitesi, Kayseri.

Çakmak, G. (2018). Mevsimlik tarım işçilerinin yaşam ve çalışma koşullarının sosyal dışlanma bă̆lamında bir araştırması: Çanakkale ili örneği. Yayımlanmamış Yüksek Lisans Tezi. Çanakkale On Sekiz Mart Üniversitesi, Çanakkale.

Dağ, A. (2016). Toplumsal cinsiyet bağlamında yaşlılık ve sosyal dışlanma. Akademik Sosyal Araştırmalar Dergisi, 4(28), 480-500. 
Dahlberg, L. Ve McKee, K.J. (2018). Social exclusion and well-being among older adults in rural and urban areas. Archives of Gerontology and Geriatrics, 79, 176-184.

Danyeli Güzel, Ö. (2017). Lezbiyen, gey, biseksüel ve transseksüellerin sosyal dı̧̧lanma deneyimleri. Yayımlanmamış Yüksek Lisans Tezi, Başkent Üniversitesi, Ankara.

Demir, A. (2018). Yoksulluk ve sosyal dışlanmanın yaşlıların yaşam tatmini üzerine etkisi. Yayımlanmamış Yüksek Lisans Tezi, İstanbul Üniversitesi, İstanbul.

Deniz, A.Ç., Balcıŏlu, M., Diktaş, A. (2016). Romanların maruz kaldıkları damgalanma ve dışlanma mekanizmaları: Uşak örneği. Tarih Okulu Dergisi, 9(15), 567-578.

Derin, M. (2017). Madde bağımlısı bireylerin sosyal dışlanma algıları: Ankara Amatem örneği. Yayımlanmamış Yüksek Lisans Tezi, Ankara Üniversitesi, Ankara.

Devicienti F. ve Poggi A. (2007). Poverty and social exclusion: two sides of the same coinor dynamically interrelated processes?.Working Paperno. 62, Laboratorio R. Revelli, Collegio Carlo Alberto, Via Real Collegio, 30-10024 Moncalieri. 25.07.2019 tarihinde http://www.laboratoriorevelli.it/ pdf/wp62.pdf adresinden erişilmiştir.

Diener, E., Emmons, R. A., Larsen, R. J., Griffin, S. (1985). The satisfaction with life scale. Journal of Personality Assessment, 49(1), 71-75.

Ergin, E. (2018). Işs-aile çatışmasının iş tatmini kariyer tatmini ve yaşam tatmini üzerine etkisi. Yayımlanmamış Yüksek Lisans Tezi, Marmara Üniversitesi, İstanbul.

Genç, Y. ve Dalkılıç, P. (2013). Yaşlıların sosyal dışlanma sendromu ve toplumsal beklentileri. International Journal of Social Science, 6(4), 461-482.

Gökçearslan-Çifci, E. (2017). Suçun yolculuğu. Ankara:Ürün Yayınları,

Gross-Manos, D. (2017). The implications of social exclusion and low material resources on children's satisfaction with life domains: a study of 12 year-olds in 13 countries. Children and Youth Services Review, 78, 129141.

Haisken-DeNew, J. ve Sinning, M. (2010). Social deprivation of 1mmigrants in Germany. Review of Income and Wealth, 56(4), 715-733.

İmanl, E. (2018). Yeni dünya düzeninin geleceği: eşitsizlik, yoksulluk ve sosyal dışlanma.Yayımlanmamış Yüksek Lisans Tezi, Uludağ Üniversitesi, Bursa. 
İskender, A. (2015). İ̧̧ görenlerin iş ve serbest zaman çatışma düzeyleri ile mesleki tükenmişlik ve yaşam tatmini ilişkisi. Yayımlanmamış Yüksek Lisans Tezi, Gazi Üniversitesi, Ankara.

Jehoel-Gijsbers G. ve Vrooman, J. C. (2007). Explaining social exclusion: a theoretical model tested in the Netherlands. The Netherlands Institute for Social Research/SCP, TheHague, July 2007.

Karakan, B. (2018). Türkiye'de sosyal dışlanma ve dezavantajlı gruplar: engelliler üzerine tanımlayıcı bir çalışma. Yayımlanmamış Yüksek Lisans Tezi, Hacettepe Üniversitesi, Ankara.

Karataşoğlu, S. (2014). Gelir seviyesinin sosyal dışlanmaya etkisi:Mardin ili örneği. Yayımlanmamış Doktora Tezi, Sakarya Üniversitesi, Sakarya.

Kenyon, S., Lyons, G. ve Rafferty, J. (2002). Transportand social exclusion: investigating the possibility of promoting inclusion through virtual mobility. Journal of Transport Geography, 10, 207-219.

Kocacık, V. ve Gökkaya, V.B. (2005). Türkiye'de çalışan kadınlar ve sorunları. C.Ü. İktisadi ve İdari Bilimler Dergisi, 6(1), 195-219.

Lee, J. ve Cagle, J.G. (2017). Social exclusion factors influencing life satisfaction among older adults. Journal of Poverty and Social Justice, 26(1), 35-50.

Mayda, F.A. ve Vurkun, S. (2018). Gelir dağılımı eşitsizliğinin toplumsal cinsiyet bağlamında değerlendirilmesi. The Journal of International Lingual, Social and Educational Sciences, 4(2), 214-228.

Mutlu, Z. (2012). Yaşl bireylerde yaşam tatmini ve sosyal destek iliş̧isinin incelenmesi.Yayımlanmamış Yüksek Lisans Tezi, Gazi Üniversitesi, Ankara.

Nurdoğan, A.K. (2018). Şehit yakınları ve gazilere sağlanan desteklerin sosyal dışlanma algisı ve yaşam kalitesinin incelenmesi. Yayımlanmamış Doktora Tezi, Süleyman Demirel Üniversitesi, Isparta.

Özgen, F. (2012). Ç.O.M.Ü. beden eğitimi ve spor yüksekokulu öğrencilerinin yaşam doyumu düzeylerinin incelenmesi. Yayımlanmamış Mezuniyet Tezi Çanakkale On Sekiz Mart Üniversitesi, Çanakkale.

Özgökçeler S. ve Bıçkı, D. (2010). Özürlülerin sosyal dışlanma boyutları: Bursa ve Çanakkale örneklerinden yansiyanlar. Sosyal Haklar Ulusal Sempozуuтu, Denizli. 21.03.2019 tarihinde http://www.sosyalhaklar.net/2010/bildiri/ozgokcer.pdf adresinden erişilmiştir.

Özhasar, B. (2013). Yoksul hanelerde sosyal dışlanmanın boyutları: Aydın ili örneği. Yayımlanmamış Yüksek Lisans Tezi, Adnan Menderes Üniversitesi, Aydin. 
Özpınar, Ş., Özpınar, Ö. ve Çondur, F. (2013). Türkiye' de üç büyük kentte cinsiyete göre sosyal dışlanma. Ekonomi Bilimleri Dergisi, 5(2), 31-44.

Öztürk, M. ve Çetin, B.I. (2009). Dünya' da ve Türkiye'de yoksulluk ve kadınlar. Journal of Yasar University, 3(11), 2661-2698

Öztürk, M.S. ve Hazer, O. (2017). Emeklilikte finansal tatmin ve yaşam tatmini. International Journal Of Eurasia Social Sciences (IJOESS),8(26), 203219.

Özyer, K., Irk, E., Anaç, S. (2015). İş tatmini ve yaşam tatmini ilişkisinde iş arkadaşlı̆̆ının aracılık rolü. C.U: Iktisadi ve Idari Bilimler Dergisi, 16(1), 261-278.

Pavot, W. ve Diener, E. (1993). Review of the satisfaction with life scale. Psychological Assessment, 3(2), 164-172.

Power, A. ve Wilson, W.J. (2000). Social exclusion and the future of cities. 01.04.2019 tarihinde http://simonpoulter.co.uk/iod/iodpdf/CASEpaper35.pdf adresinden erişilmiştir.

Robila, M. (2006). Economic pressure and social exclusion in Europe. The Social Science Journal, 43, 85-97.

Shields M. A., Price S. W., Wooden M. (2009). Life satisfaction and the economic and social characteristics of neighbourhoods. J Popul Econ, 22(2) 421-443.

Şener, B. (2018). Avrupa Birliği'nin göç politikaları bağlamında göçmenlerin sosyal dışlanması. Yayımlanmamış Yüksek Lisans Tezi, Marmara Üniversitesi, İstanbul.

Tabuk, M.E. (2009). Elit sporcularda iş- aile çatışması ve yasam tatmini ilişkisinin incelenmesi. Yayımlanmamış Yüksek Lisans Tezi, Erciyes Üniversitesi, Kayseri.

Topgül, S. (2016). Sosyal dışlanma ve göç: Mülteci işçiler örneği. Sosyoloji Dergisi, 33, 269-289.

Yalçın, B. (2018). Algilanan örgütsel destek ve sosyal desteğin yaşam tatminine etkisi: TSK mensubu rütbeli gaziler üzerinde bir araştırma. Yayımlanmamış Yüksek Lisans Tezi, Çankaya Üniversitesi, Ankara.

Yerlisu Lapa, T., Ağyar, E. ve Bahadır, Z. (2012). Yaşam tatmini, serbest zaman motivasyonu, serbest zaman katılımı: Beden eğitimi ve spor öğretmenleri üzerine bir inceleme:Kayseri ili örneği. Spormetre Beden Ĕğitimi ve Spor Bilimleri Dergisi, 10(2) 53-59. 
Yılmaz, Ş. (2018). Engelli çocuğa sahip olup olmama ile ailelerin bilgi-iletişim teknolojilerine bağımlılık düzeyleri ve sosyal dışlanma etkisinin incelenmesi.Yayımlanmamış Yüksek Lisans Tezi, Hasan Kalyoncu Üniversitesi, Gaziantep.

Yiğit, R., Dilmaç, B. ve Deniz, M.E. (2011). İş ve yaşam doyumu: Konya emniyet müdürlüğü alan araştırması. Polis Bilimleri Dergisi, 13(3), 1-18.

Yusufoğlu, Ö.Ş. ve Kızmaz, Z. (2016). Parçalanmış ailelerde yoksulluk ve sosyal dışlanma: Elâzığ örneği. Social Sciences (NWSASOS), 11(1), 27-40.

Yücetürk, O.K. (2018). Lise öğrencilerinde sosyal dışlanmanın akran ilişkileri ve mükemmeliyetçilik ile ilişkisi. Yayımlanmamış Yüksek Lisans Tezi, Üsküdar Üniversitesi, İstanbul.

\section{Kaynakça Bilgisi / Citation Information}

Serpen, A. Z., Kalaycı, E. ve Parlak, E. (2019). Sakarya Kadın Eğitim ve Kültür Merkezinden hizmet alan kadınlarda sosyal dışlanma ve yaşam tatmininin incelenmesi. OPUS-Uluslararası Toplum Araştırmaları Dergisi , 14(20), 1312-1335. DOI: 10.26466/ opus.611692. 